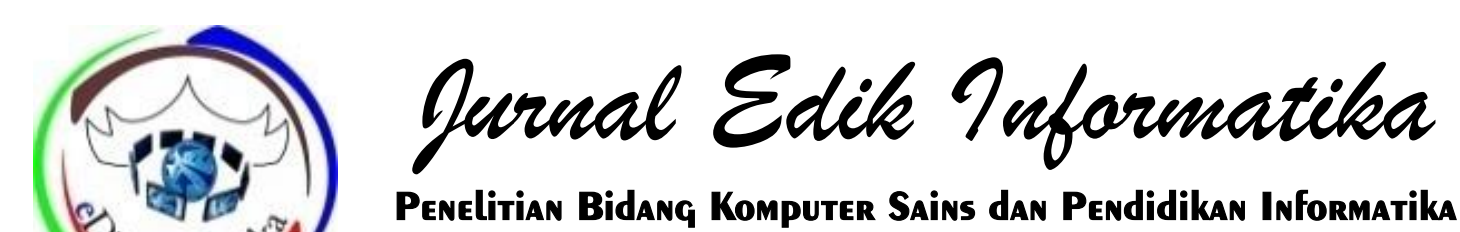

Website: ejournal.stkip-pgri-sumbar.ac.id/index.php/eDikInformatika

\title{
SISTEM INFORMASI PEMESANAN TIKET KAPAL MENTAWAI FAST KOTA PADANG BERBASIS WEB
}

\author{
Julianus Saeppu ${ }^{1}$, Thomson Mary ${ }^{2}$, Heri Mulyono ${ }^{3}$ \\ ${ }^{1,2,3}$ STKIP PGRI Sumatera Barat \\ saeppu95@gmail.com
}

INFO ARTIKEL

\section{Diterima:}

15 Oktober 2019

Direview:

24 Oktober 2019

Disetujui:

26 November 2019

Keywords:

Information Systems,

Tickets, Web, PHP,

SDLC, UML.

\begin{abstract}
Mentawai Fast is a company engaged in the field of transportation services. The problem is that there is no webbased ship ticket booking information system, ticket purchases are still manual or a passenger must go to the agent to buy tickets and requires a long time.In this system, it starts with analyzing the current system, which is done by output design, input design, file design. The research method used is SDLC (System Devolopment Life Cyle) with stages a). Planning, b) Analysis, c) Designing Systems and Software, d). Implementation, using design tools, namely UML (Unified Modeling Language).With the design of this ordering information system, it is expected to provide maximum service to customers and minimize errors in data processing. The benefits of this ordering information system are expected to improve service to customers and facilitate the transaction process faster and easier.
\end{abstract}

\section{PENDAHULUAN}

Pada era globalisasi sekarang ini, penggunaan sistem informasi telah mengalami perkembangan yang pesat di berbagai bidang, baik di bidang ekonomi, kesehatan, pendidikan, pemerintahan, maupun dibidang lainnya. Perkembangan tersebut mendorong perusahaanperusahaan untuk menggunakan sistem informasi sesuai dengan kebutuhan perusahaan dengan tujuan menggantikan berbagai fungsi dan kerja manusia yang berguna untuk membantu dan memudahkan manusia dalam melakukan pekerjaannya. Salah satu bidang yang terpengaruh diera globalisasi dalam penggunaan sistem informasi diantara bidang transportasi.

Transportasi adalah salah satu kebutuhan vital bagi masyarakat, baik transportasi udara, darat maupun laut. Transportasi laut di Mentawai merupakan sarana paling penting dalam memajukan perekonomian nasional. Banyak orang memilih kapal eksekutif untuk perjalanan karena cepat, nyaman, dan aman. Sebelum melakukan perjalanan calon penumpang kapal eksekutif harus terlebih dahulu memesan tiket ke agen mengenai kemana tempat yang akan dituju dan kapan jadwal keberangkatannya. Peneliti melihat konsumen mengalami kesulitan 
dalam pemesanan tiket karena jarak dan waktu hanya untuk memesan tiket.

Transportasi Informasi yang terkoordinir mempunyai pengaruh penting yaitu manajer dapat memantau kondisi manajemen kapal agar dapat berjalan semestinya. Pengelolaan data yang sudah terkomputerisasi memudahkan pihak kapal dalam mencari data yang diperlukan sesuai dengan informasi dari pemesan tiket. Seiring dengan kemajuan zaman yang semakin pesat, maka konsumen di tuntut untuk mengikuti perkembangan dari dunia itu sendiri, kadang konsumen pun tidak memandang waktu dalam melakukan aktivitas sehari-hari, mereka membutuhkan sesuatu yang simpel, salah satunya adalah masalah pemesanan tiket pada Mentawai Fast Padang. Saat ini banyak agen yang mengolah data pemesanan tiket kapal eksekutif belum terkomputerisasi, salah satunya agen untuk kapal eksekutif Mentawai Fast yang bertempat di Padang sebagai lokasi penelitian. Saat ini operasional kerja kapal memiliki cukup banyak kendala seperti pemesanan tiket yang masih manual atau seorang pembeli tiket harus ke agen untuk membeli tiket, banyak penumpang yang mengeluh karena tidak dapat tiket serta banyaknya antrian dalam pembelian tiket sehingga membutuhkan waktu yang lama, lambat dalam pemberian informasi kepada calon pembeli tiket kapal serta penyimpanan laporan data-data pemesanan tiket belum terorganisir dengan baik. Oleh karena itu dibawah ini terdapat beberapa pendapat para ahli.

Menurut Tata Sutabri (2016:6) Sistem pada dasarnya adalah sekelompok unsur yang erat hubungannya satu dengan yang lain, yang berfungsi bersama-sama untuk mencapai tujuan tertentu.

Menurut Tata Sutabri (2016:25) Informasi adalah sebuah istilah yang tidak tepat pemakaiannya secara umum, informasi dapat mengenai data mentah, data tersusun, kapasitas sebuah saluran komunikasi dan lain sebagainya.

Menurut Tata Sutabri (2016:40) Sistem informasi adalah suatu sistem di dalam suatu organisasi yang mempertemukan kebutuhan pengolahan transaksi harian yang mendukung fungsi operasi organisasi yang bersifat manajerial dengan kegiatan strategi dari suatu organisasi untuk dapat menyediakan kepada pihak luar tertentu dengan laporan-laporan yang diperlukan.

Pemesanan adalah suatu aktifitas yang dilakukan oleh konsumen sebelum membeli. Untuk mewujudkan kepuasan konsumen maka perusahaan harus mempunyai sebuah sistem pemesanan yang baik. Menurut Kamus Besar Bahasa Indonesia yang dimaksud pemesanan adalah "proses, perbuatan, cara memesan (tempat, barang, dan sebagainya) kepada orang lain".

Menurut Rahmat dan Octaviano (2016:11) Tiket adalah salah satu dokumen perjalanan yang dikeluarkan oleh perusahaan untuk menerapkan suatu kontrak tertulis satu pihak yang berisikan ketentuan yang harus dipenuhi oleh penumpang selama memakai jasa tiket dan data penumpang yang mempunyai masa periode waktu tertentu.

Menurut Tama (2012:360) Website atau situs dapat diartikan sebagai kumpulan halaman-halaman yang digunakan untuk menampilkan informasi, teks, gambar diam atau bergerak, animasi, suara, dan atau gabungan dari semuanya itu, baik yang bersifat statis maupun dinamis yang membentuk satu rangkaian bangunan yang saling berkait dimana masing masing dihubungkan dengan jaringan- jaringan halaman.

\section{METODE PENELITIAN}

Metode penelitian yang digunakan adalah metode System Development Life 
Cycle (SDLC). SDLC mempunyai 4 tahapan dalam pembentukan sistem informasi yaitu:

a) Perencanaan

Pada tahap ini lebih fokus pada penafsiran kebutuhan dan diagnosa masalah dengan mendefenisikan sasaran tujuan dari sistem informasi dengan dibagunnya sistem informasi pemesanan tiket kapal Mentawai Fast untuk mengganti proses yang masih manual.

b) Analisis

Menganalisis, mendefinisikan masalah dan kemungkinan solusinya. Pada tahap ini dilakukan analisa terhadap sistem yang sudah ada di Mentawai Fast dan dijumpai masalah yaitu sulitnya penumpang dalam memesan tiket kapal, kemudian memakan waktu lama saat memesan tiket kapal. Dengan menggunakan sistem informasi diharapkan akan dapat mengatasi maslah tersebut.

c) Perancangan

Mengimplementasikan model yang diinginkan pemakai. Alat yang digunakan adalah:

\section{1) Unified Modeling Language (UML)}

2) Perancangan layar tampilan input output

3) Rancangan menu program sebagai alat perancangan struktur tampilan.

d) Implementasi

Tahap ini merupakan penerapan dan evaluasi serta memikirkan keberlanjutan sistem untuk dapat menjawab kebutuhan sistem sepanjang sistem digunakan oleh user. Untuk mencapai hal tersebut maka sistem perlu dirawat dan dipelihara untuk keberlanjutan sistem.
UML merupakan bahasa visual untuk pemodelan dan komunikasi mengenai sebuah sistem dengan menggunakan diagram dan teks-teks pendukung. UML muncul karena adanya kebutuhan pemodelan visual untuk menspesifikasikan, menggambarkan, membangun, dan dokumentasi dari sistem perangkat lunak.

\section{Use Case Diagram}

Use Case Diagram mendeskripsikan sebuah interaksi antara satu atau lebih aktor dengan sistem informasi yang akan dibuat. Secara kasar, use case diagram digunakan untuk mengetahui fungsi apa saja yang ada di dalam sebuah sistem informasi dan siapa saja yang berhak menggunakan fungsi itu.

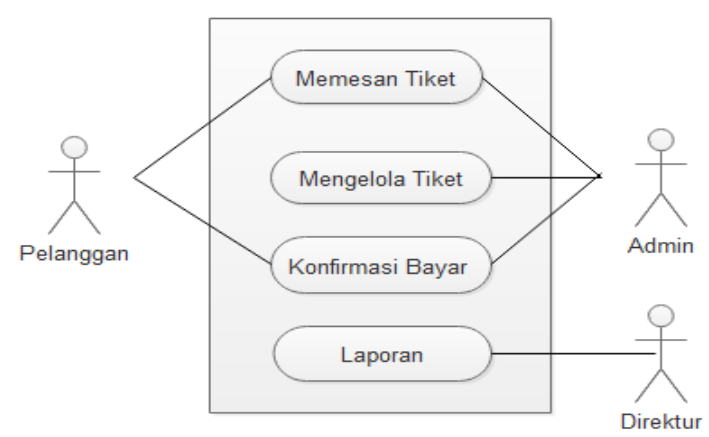

Gambar 1. Use Case Diagram Bundary Sistem Pemesanan Tiket Kapal

\section{Activity Diagram}

Activity diagram menggambarkan bagaimana aktivitas yang terjadi dalam sistem yang akan dirancang. Activity diagram sama seperti halnya flowchart yang menggambarkan proses yang terjadi antara actor dan sistem.

a. Activity Diagram Admin

Activity diagram $\begin{array}{r}\text { admin } \\ \text { menggambarkan } \\ \text { bagaimana }\end{array}$
aktivitas yang terjadi pada admin
dan sistem. Dapat dilihat pada
Gambar 2.

$\begin{array}{lr}\text { Activity diagram } & \begin{array}{r}\text { admin } \\ \text { menggambarkan }\end{array}\end{array}$ aktivitas yang terjadi pada admin Gambar 2. 


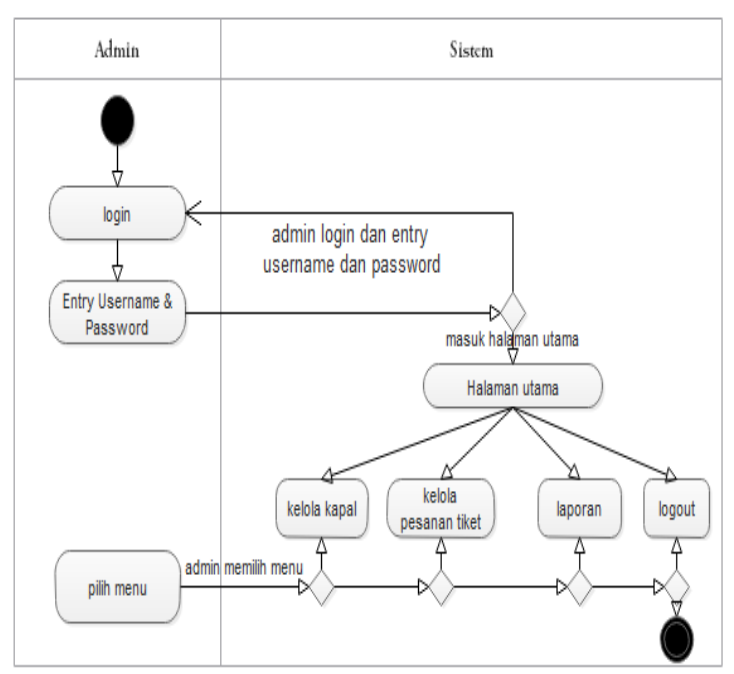

Gambar 2. Activity Diagram Admin

b. Activity Diagram Pelanggan Activity diagram pelanggan menggambarkan bagaimana aktivitas yang terjadi pada pelanggan dan sistem. Dapat dilihat pada Gambar 3.

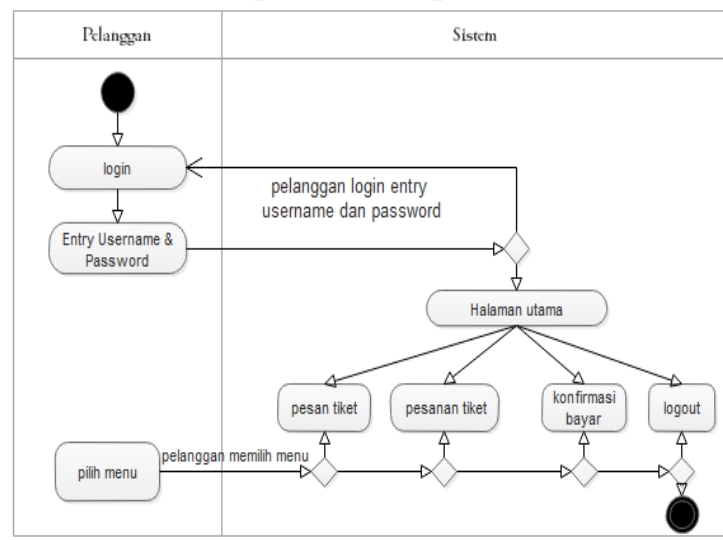

Gambar 3. Activity Diagram Pelanggan

\section{Sequence Diagram}

Sequence diagram menjelaskan interaksi objek yang disusun dalam suatu urutan waktu. Urutan waktu yang dimaksud adalah urutan kejadian yang dilakukan oleh seorang actor dalam menjalankan sistem. Sequence diagram menunjukkan bagaimana detail opeasi dilakukan, pesan apa yang dikirim dan kapan.

a. Sequence Diagram Pesan Tiket Pelanggan mengawali interaksi dengan sistem dengan akses menu utama. Menu utama terdapat menu pesan tiket, pelanggan dapat melakukan pemesanan tiket kapal. Dari penjelasan di atas sequence diagramnya dapat dilihat pada Gambar 4.

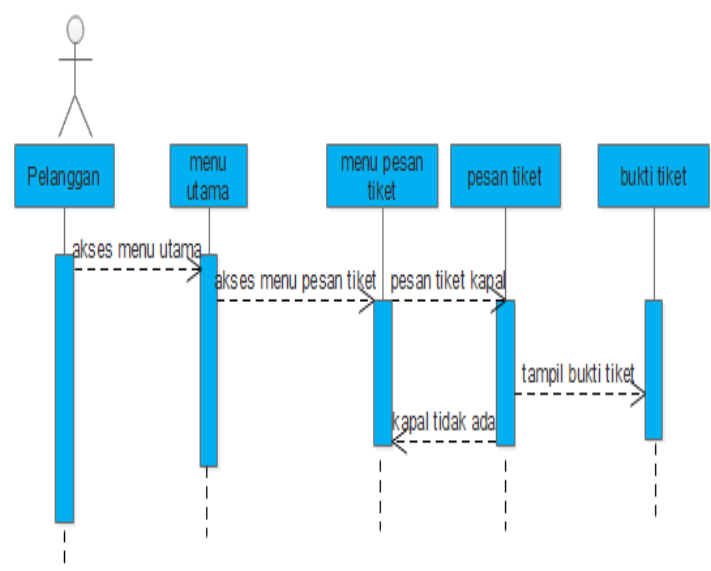

Gambar 4. Sequence Diagram Pesan Tiket

b. Sequence Diagram Konfirmasi Bayar Pelanggan mengawali interaksi dengan sistem dengan akses menu utama. Menu utama terdapat menu pesanan tiket, pelanggan dapat melakukan konfirmasi pembayaran. Dari penjelasan di atas sequence diagramnya dapat dilihat pada Gambar 5.

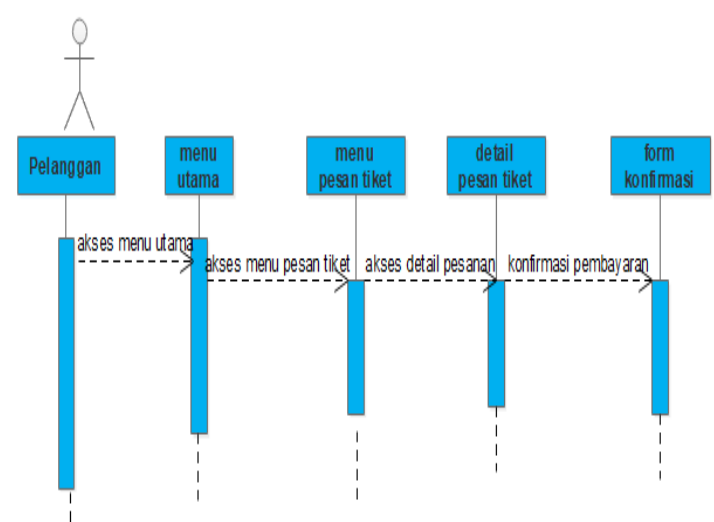

Gambar 5. Sequence Diagram Konfirmasi Bayar

c. Sequence Diagram Kelola Pesanan Tiket

Admin mengawali interaksi dengan sistem dengan akses menu pesanan tiket, admin dapat mengelola 
pesanan tiket. Dari penjelasan di atas sequence diagramnya dapat dilihat pada Gambar 6.

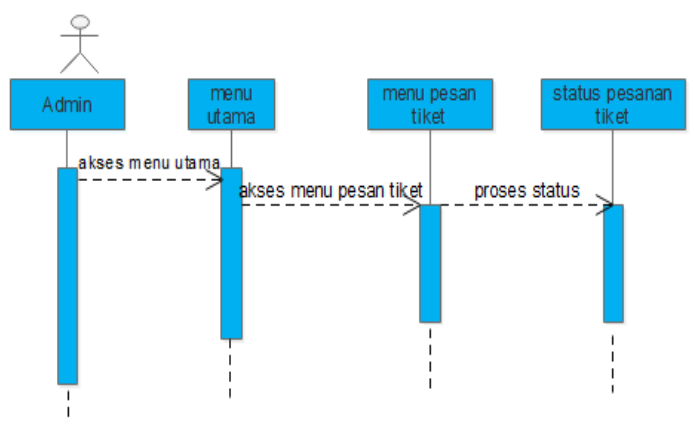

Gambar 6. Sequence Diagram Kelola Pesanan Tiket

d. Sequence Diagram Laporan

Admin mengkases menu utama setelah itu mengakses menu laporan, admin dapat mencetak laporan. Dari penjelasan di atas sequence diagramnya dapat dilihat pada Gambar 7.

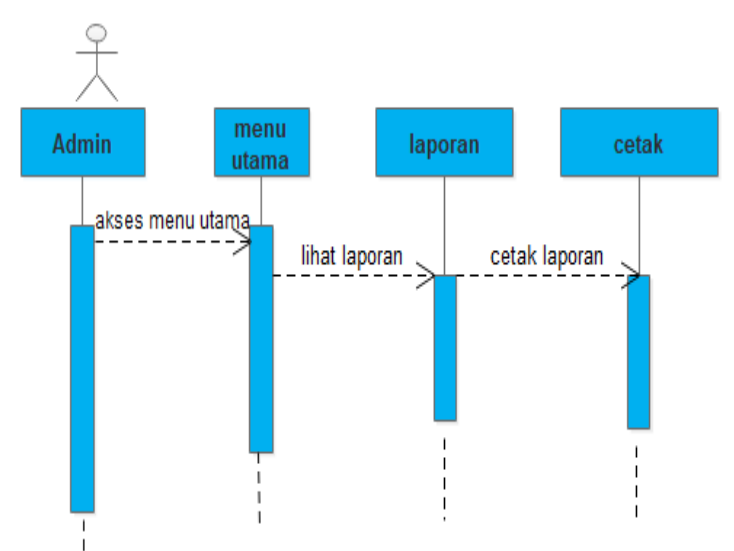

Gambar 7. Sequence Diagram Laporan

\section{Class Diagram}

Class diagram memberikan gambaran hubungan antara tabel-tabel yang ada dalam database. Masingmasing class memiliki attribute dan metoda atau fungsi sesuai dengan proses yang terjadi. Class diagram dapat dilihat pada Gambar 8.

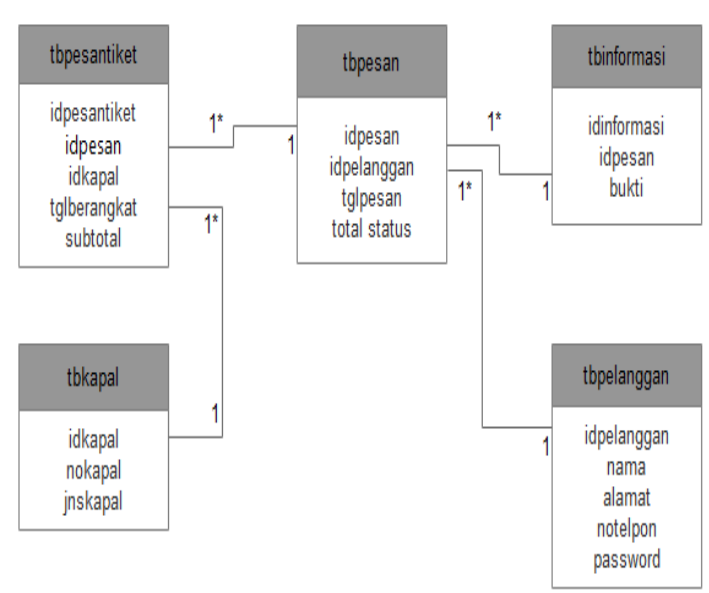

Gambar 8. Class Diagram

\section{HASIL DAN PEMBAHASAN}

Tahap implementasi merupakan tahap terakhir dalam menggambarkan sistem, yaitu meletakan sistem supaya siap dioperasikan. Implementasi berguna untuk memudahkan penerapan sistem yang disiapkan agar pengentrian data sampai pada penyajian informasi sesuai dengan prosedur yang telah direncanakan.

\section{Tampilan Home Mentawai Fast}

Dimana pada form ini adalah form awal yang di tampilkan. Form home dapat di lihat pada Gambar 9.

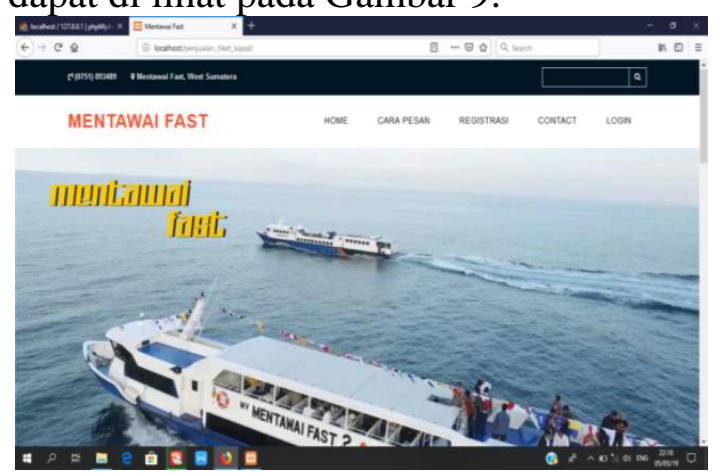

Gambar 9. Form Home Mentawai Fast

\section{Form Registrasi Member}

Pada form registrasi ini konsumen atau member harus mengisi data yang di butuhkan dengan benar dan valid. Form registrasi dapat kita lihat pada Gambar 10. 

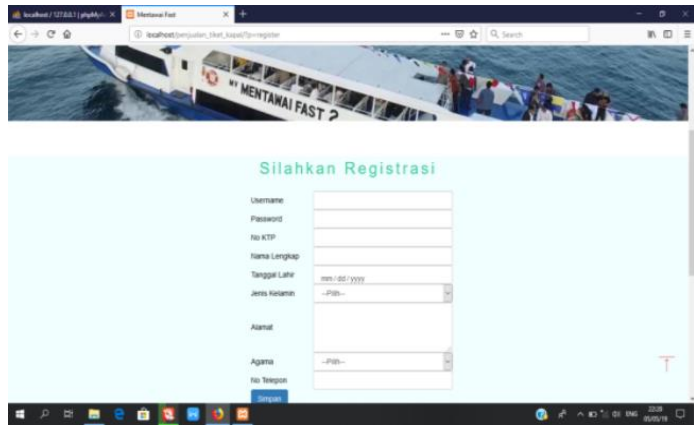

Gambar 10. Form Registrasi

\section{Form Login Member}

Pada form ini konsumen harus mengisi data level dengan memilih member dan menginputkan username, dan password telah di daftarkan saat registrasi. Form login member dapat dilihat pada Gambar 11.

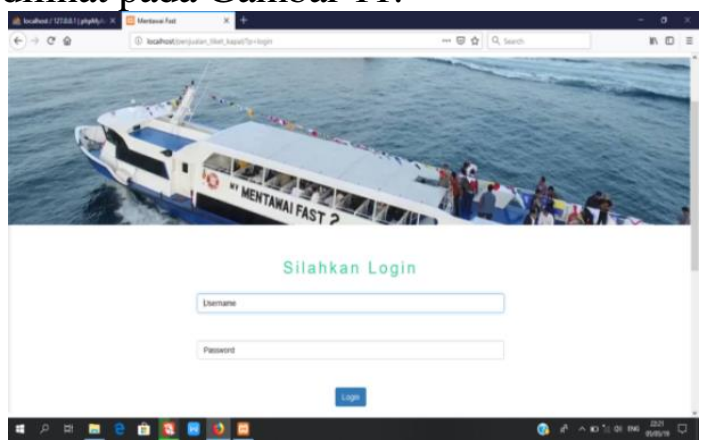

Gambar 11. Form Login Member

\section{Form Pemesanan Tiket Kapal}

Pada form pemesanan tiket ini, member atau konsumen harus memilih tujuan, banyak tiket, dan tanggal keberangkatan yang di inginkan oleh member atau konsumen itu sendiri. Pada form yang pertama member atau pelanggan harus memilih tujuan yang di inginkan. Dapat dilihat pada Gambar 12.

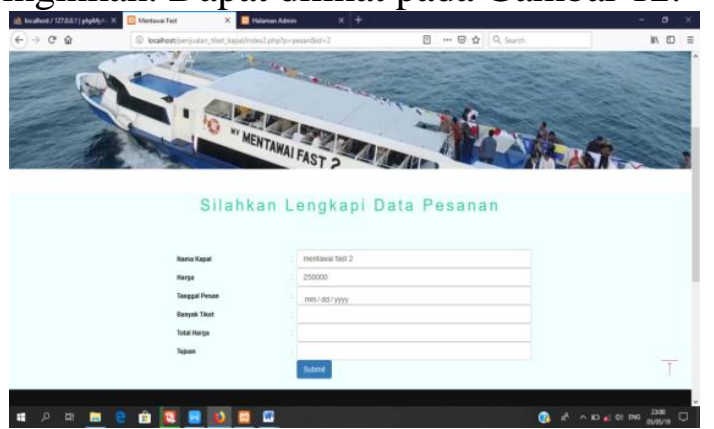

Gambar 12. Form Pemesanan Tiket Kapal
Julianus Saeppu, Thomson Mary, Heri Mulyono

\section{Form Tiket}

Pada form ini akan tampil bentuk tiket kapal member atau konsumen yang telah di pesan dan siap untuk di print sebagai bukti saat waktu keberangkatan. Form dapat di lihat pada Gambar 13.

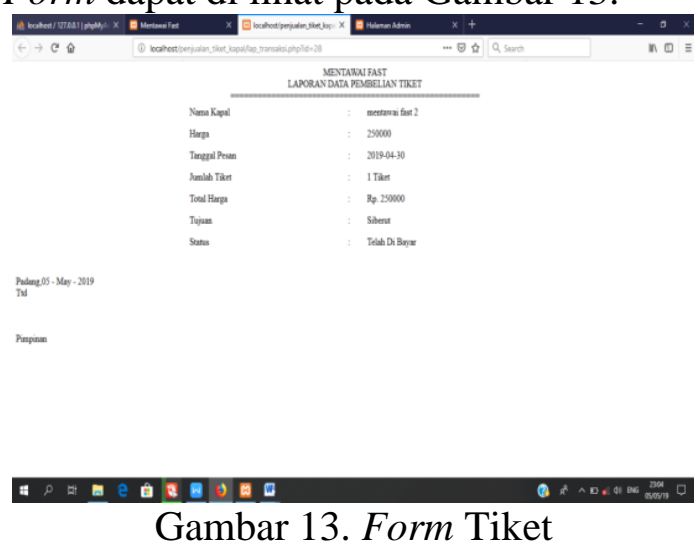

Pengujian sistem informasi pemesanan tiket kapal Mentawai Fast di Kota Padang berbasis web menggunakan metode pengujian black box yang akan diuji adalah masing-masing modul dengan menggunakan data yang sudah dipersiapkan terlebih dahulu dan membandingkan hasilnya dengan kriteria yang sudah diujikan.

\section{KESIMPULAN}

Dari hasil penelitian Sistem Informasi Pemesanan Tiket Kapal Mentawai Fast Padang ini maka dapat disimpulkan bahwa:

1. Dengan memanfaatkan sistem Informasi ini dapat memberikan informasi pemesanan tiket kapal kepada pelanggan atau calon pembeli tiket kapal.

2. Sistem informasi pemesanan tiket kapal Mentawai Fast Padang dapat membantu dalam penyimpanan laporan data-data pemesanan tiket terorganisir dengan baik.

3. Pengolahan data dan laporan pemesanan tiket kapal Mentawai Fast Padang sudah terintegrasi database, sehingga proses pengolahan data lebih efisien. 


\section{DAFTAR PUSTAKA}

Prahasta, E. (2014). Sistem Informasi Geografis Konsep-Konsep Dasar (Spektif Geodesi \& Geomatika).

Rachmatullah, R. (2015). Perancangan Sistem Pemesanan Tiket Bus Online Berbasis Web, 4(1), 25-29.

Rossa A.s dan M. Shalahuddin. (2016). Rekayasa Perangkat Lunak (Terstruktur dan Berorientasi Objek).

Tata Sutabri. (2016). Analisis Sistem Informasi. 